\title{
Comparison of the 18-month outcome after the treatment of osteoporotic insufficiency fractures by means of balloon sacroplasty (BSP) and radiofrequency sacroplasty (RFS) in comparison: a prospective randomised study
}

\author{
Reimer Andresen ${ }^{1} \cdot{\text { Sebastian } \text { Radmer }^{2} \cdot \text { Julian Ramin Andresen }}^{3} \cdot$ \\ Hans-Christof Schober ${ }^{4}$
}

Received: 8 May 2016/Revised: 26 November 2016/Accepted: 25 December 2016/Published online: 9 January 2017

(C) The Author(s) 2017. This article is published with open access at Springerlink.com

\begin{abstract}
Purpose The objective of this prospective, randomised study was to examine the feasibility and clinical outcome of balloon sacroplasty and radiofrequency sacroplasty.

Methods In 40 patients with a total of 57 sacral fractures, CT-guided cement augmentation was performed by means of BSP or RFS. For BSP, the balloon catheter was inflated and deflated in the fracture zone, and the hollow space, thus, created was then filled with PMMA cement. For RFS, the spongious space in the fracture zone was initially extended using a flexible osteotome, and the highly viscous PMMA cement, activated by radiofrequency, was then inserted into the prepared fracture zone. Pain intensity was determined on a VAS before the intervention, on the second day, and 6,12 and 18 months after the intervention. The results were tested for significance by means of paired Wilcoxon rank-sum tests and Mann-Whitney $U$ tests.

Results BSP and RFS were technically fully feasible in all patients. An average of $6.3 \mathrm{ml}$ cement per fracture was inserted in the BSP group and an average of $6.1 \mathrm{ml}$ per fracture in the RFS group. Leakage could be ruled out for both procedures. The mean pain score on the VAS before
\end{abstract}

Reimer Andresen

randresen@wkk-hei.de

1 Institute of Diagnostic and Interventional Radiology/ Neuroradiology, Westkuestenklinikum Heide, Academic Teaching Hospital of the Universities of Kiel, Luebeck and Hamburg, Esmarchstraße 50, 25746 Heide, Germany

2 Centre for Orthopaedics, Berlin, Germany

3 Sigmund Freud University, Vienna, Austria

4 Department of Internal Medicine I, Municipal Hospital Suedstadt Rostock, Academic Teaching Hospital of the University of Rostock, Rostock, Germany the intervention was $8.6 \pm 0.55$ in the BSP group and $8.8 \pm 0.58$ in the RFS group. On the second postoperative day, a significant pain reduction was seen $(p<0.001)$, with an average value of 2.5 (BSP $\pm 0.28, \mathrm{RFS} \pm 0.38$ ) for both groups. After $6(12 ; 18)$ months, these values were stable for the BSP group at $2.3 \pm 0.27(2.3 \pm 0.24$; $2.0 \pm 0.34)$ and for the RFS group at $2.4 \pm 0.34$ $(2.2 \pm 0.26 ; 2.0 \pm 0.31)$. With regard to pain, exceedance probability values of $p=0.86$ ( 6 months), $p=0.94$ (12 months) and $p=1$ (18 months) were seen, so that neither treatment method leads to differences in results. Conclusions BSP and RFS are interventional, minimally invasive procedures that enable reliable cement augmentation and achieve equally good clinical outcomes in the medium term.

Keywords Balloon sacroplasty - Radiofrequency sacroplasty · Insufficiency fracture - Sacrum · Pain therapy $\cdot$ Cement augmentation

\section{Introduction}

Since insufficiency fractures of the sacrum were first described by Lourie in 1982 [1], knowledge about the clinical signs and the correct use of imaging diagnostics has improved, which means that these fractures are being detected increasingly frequently [2]. In particular when elderly patients with osteoporosis are concerned, the sudden occurrence of deep-seated intense back pain is significantly correlated with the incidence of a newly developed sacral fracture [3-5].

For rapid pain reduction, as a minimally invasive form of treatment, cement can be inserted via hollow needles, analogously to vertebroplasty [6-10]. Whitlow et al. [11] 
substantiate this with an equally good clinical improvement when comparing vertebral and sacral cement augmentation. However, leakages are possible with this technique and they are not always free of symptoms [12].

With balloon sacroplasty (BSP) and radiofrequency sacroplasty (RFS), interventional, minimally invasive treatment options have now become established that, as a result of the methods used, minimise leakages and the complications with which they are associated [13, 14].

The objective of this prospective and randomised study was to examine and compare the feasibility and clinical outcome of these two different treatment forms, BSP and RFS.

\section{Materials and methods}

A sacral fracture was detected by CT and MRI in 40 patients (36 women with an average age of $78.4\{70-93\}$ years, 4 men with an average age of $72.7\{68-83\}$ years). The fractures were classified according to Denis et al. [15]. Conservative treatment initially performed over a period of $>3$ weeks including analgesic medication, immobilisation and physiotherapy did not bring any satisfactory reduction of the severe, disabling pain. The indication for cement augmentation was established in an interdisciplinary case conference, whereby only patients with a pain level of $>5$ on a visual analogue scale (VAS) were accepted. The patients were informed about the possible procedures; the respective procedure applied was randomly assigned by drawing lots on the day of the intervention. All sacroplasties were carried out by the same interventional radiologist (RA). To prevent changes in position during cement augmentation, the intervention was performed under intubation anaesthesia and anaesthetic monitoring. Single-shot antibiotic prophylaxis (cefazoline $2 \mathrm{~g}$ i.v.) was given routinely immediately prior to the intervention. For both procedures, either the short axis or the transiliac axis was chosen as an approach to the fracture zone in the sacrum [16] (Fig. 1). For BSP, the balloon catheter (15 or $20 \mathrm{~mm}$ balloon, Kyphon ${ }^{\circledR}$ Medtronic) was inflated and deflated in the fracture zone 1-3 times, and the hollow space created was then filled with polymethyl methacrylate (PMMA) cement using a low-pressure procedure under CT guidance [13], (Fig. 2). For RFS, a Jamshidi needle was initially advanced into the respective fracture zone of the sacrum, analogously to the BSP via the short or transiliac axis. After removing the inner needle, a flexible osteotome was inserted through the positioned hollow needle and used to extend the spongious space in the fracture zone and thus prepare a cavity for the cement filling. The highly viscous PMMA cement ( $\mathrm{ER}^{2}$ Bone Cement, DFine), activated by radiofrequency, was then inserted into the prepared fracture zone through a substituted screw cannula. Cement augmentation was performed discontinuously under instrumental guidance at $1.3 \mathrm{ml} / \mathrm{min}$ (STABILIT ${ }^{\circledR}$ Vertebral Augmentation System-Radiofrequency Kyphoplasty from DFine) under CT control [14], (Fig. 3). Cement leakages were determined in CT images and conventional radiographs on the day after the intervention. Pain intensity was documented on a VAS before the intervention, on the second day, and 6, 12 and 18 months after the intervention. Statistical analysis was performed with Prism 5 software (GraphPad). Mann-Whitney test was used for unpaired values (BSP vs RFS) and Wilcoxon signed rank test was used for paired values (Pre OP vs 2nd day, 2nd day vs 6 months, etc.) to evaluate differences between two variables. Statistical significance was set at $* p<0.05$, $* * p<0.005$, and $* * * p<0.0005$. Additionally occurring complications were recorded, and finally the patients were asked to state how satisfied they were using a standardised questionnaire after 6 and 18 months.

\section{Results}

Of the 40 patients, the sacral fracture was unilateral in 20 women and 3 men and bilateral in 16 women and 1 man. The 57 fractures, thus, treated did not show any significant difference with regard to distribution and localisation when comparing the BSP group with the RFS group. As regards fracture type, 27 of 57 or $48.1 \%$ were type 1, 20 of 57 or $35.2 \%$ were type 1 and 2, 7 of 57 or $13 \%$ were type 1, 2 and 3,3 of 57 or $3.7 \%$ were type 2 , and 0 of 57 or $0 \%$ were type 3 fracture zones (Fig. 4).

BSP and RFS were unproblematic and technically fully feasible in all patients.

An average of 6.3 (3-8) $\mathrm{ml}$ cement per fracture was inserted in the BSP group and an average of 6.1 (3-9) ml per fracture in the RFS group. The different approaches did not have any influence on the amounts of cement inserted. The CT control showed sufficient cement distribution along the fracture zone in the sacrum, whereby a leakage in the direction of the neuroforamina, the sacroiliac joints, the visceral surface or into the dorsal soft-tissues, or into the discal space between the lumbar vertebral body L5 and the sacral vertebral body S1, could be ruled out for both procedures.

The mean pain score on the VAS before the intervention was $8.6 \pm 0.55$ in the BSP group and $8.8 \pm 0.58$ in the RFS group. On the second postoperative day, a significant pain reduction was seen on the basis of paired Wilcoxon rank-sum tests taking into account ties $(p<0.001$ in each case) for both groups, with an average value of $2.5 \pm 0.28$ for the BSP group and $2.5 \pm 0.38$ for the RFS group. After $6(12 ; 18)$ months, these values were stable at $2.3 \pm 0.27$ $(2.3 \pm 0.24 ; 2.0 \pm 0.34)$ for the BSP group and $2.4 \pm 0.34$ $(2.2 \pm 0.26 ; 2.0 \pm 0.31)$ for the RFS group (Fig. 5). 
Fig. 1 Schematic

representation (already used in [14]) of the classification of the fracture zones according to Denis et al. [15] on the left. On the right, presentation of the approaches used via the transiliac and short axis
Fracture zone sand approaches

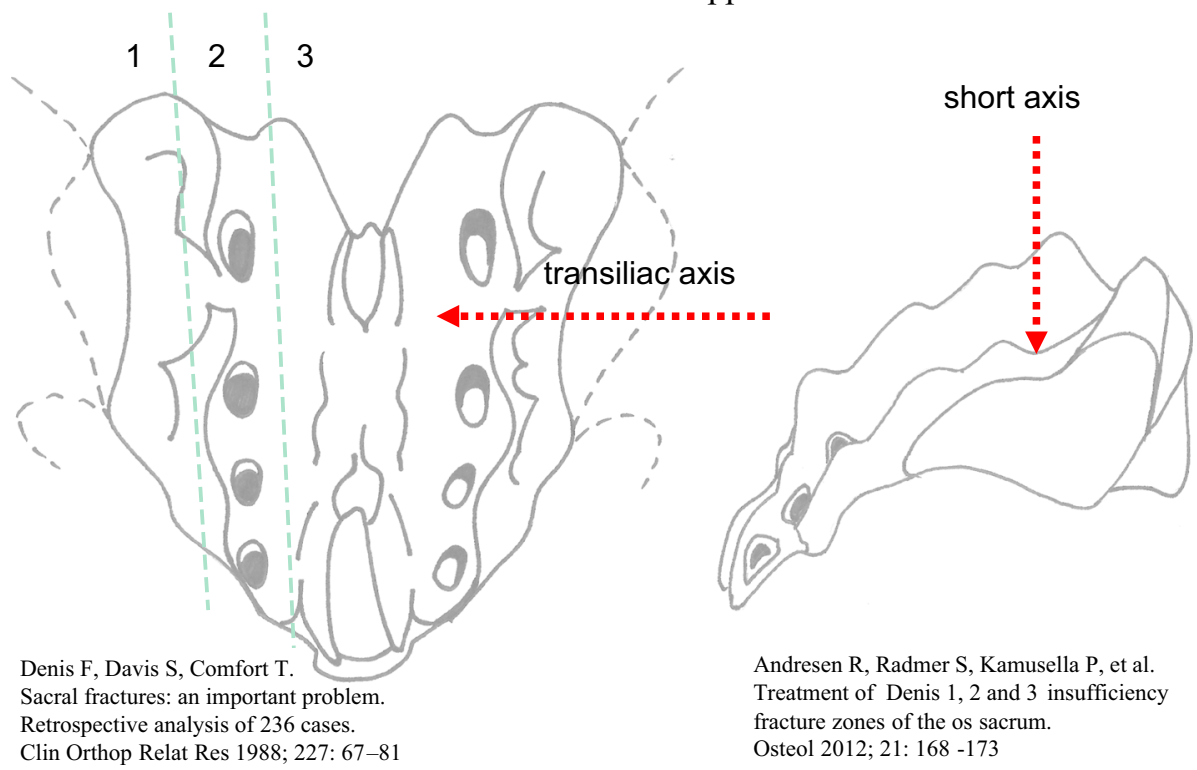

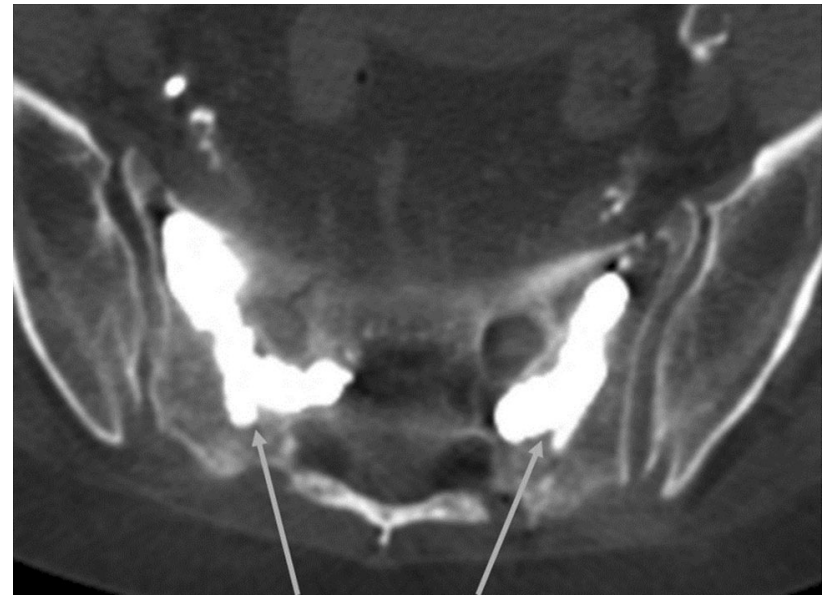

Fig. 2 Image of the cement fillings introduced by means of BSP. A Denis type 1 and 2 fracture was treated on the right and a Denis type 1 fracture on the left. On both sides, the approach was via the short axis. On both sides, the cement fillings are located centrally in the fracture zones, and cement leakage can be ruled out

With regard to pain, the Mann-Whitney $U$ tests showed exceedance probability values for the BSP group and RFS group in comparison for months 6,12 and 18 , respectively, of $p=0.86$ (6 months), $p=0.94$ (12 months) and $p=1$ (18 months), so that both treatment methods lead to the same results.

After 6 ( 40 of 40 patients questioned) and 18 months (36 of 40 patients questioned), equally high patient satisfaction was found in both groups, with all of the patients surveyed stating that they would undergo the intervention again.

No cases of infection or bleeding were observed postintervention. As a result of the elimination of the disabling pain, all of the patients could initially be remobilised. Over

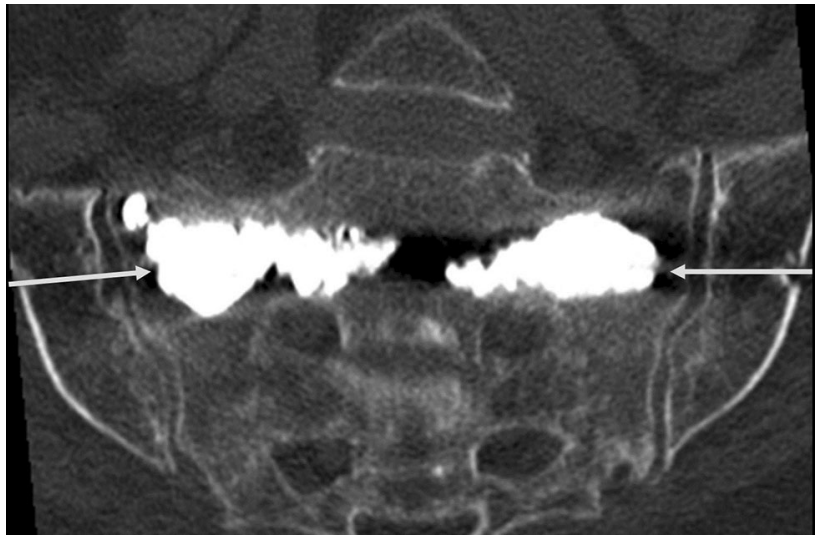

Fig. 3 Image of the cement fillings introduced by means of RFS. A Denis type 1 and 2 fracture was treated on both sides. On both sides, the approach was via the transiliac axis. On both sides, the cement fillings are located centrally in the fracture zones, and cement leakage can be ruled out

the further course, physical examinations did not produce any evidence of renewed fractures in the pelvic region. One female patient died of pneumonia and one male patient of lung cancer in the BSP group, while one female patient died after a stroke and another of colon cancer in the RFS group.

\section{Discussion}

The technical feasibility of cement augmentation in the fracture zone of a sacral insufficiency fracture could initially be shown for the vertebroplasty method [17], followed by balloon kyphoplasty [18] and then radiofrequency augmentation [19]. In the meantime, the clinical benefit achieved by 
Fig. 4 Distribution of the insufficiency fractures in the sacrum according to Denis et al. [15]. Unilateral fractures were found in 23 patients and bilateral fractures in 17 patients, which means that a total of 57 fractures were treated in 40 patients. A Denis type 1 and Denis type 1 and 2 fracture was found most commonly, followed by a Denis type 1,2 and 3 as well as Denis type 2 fracture

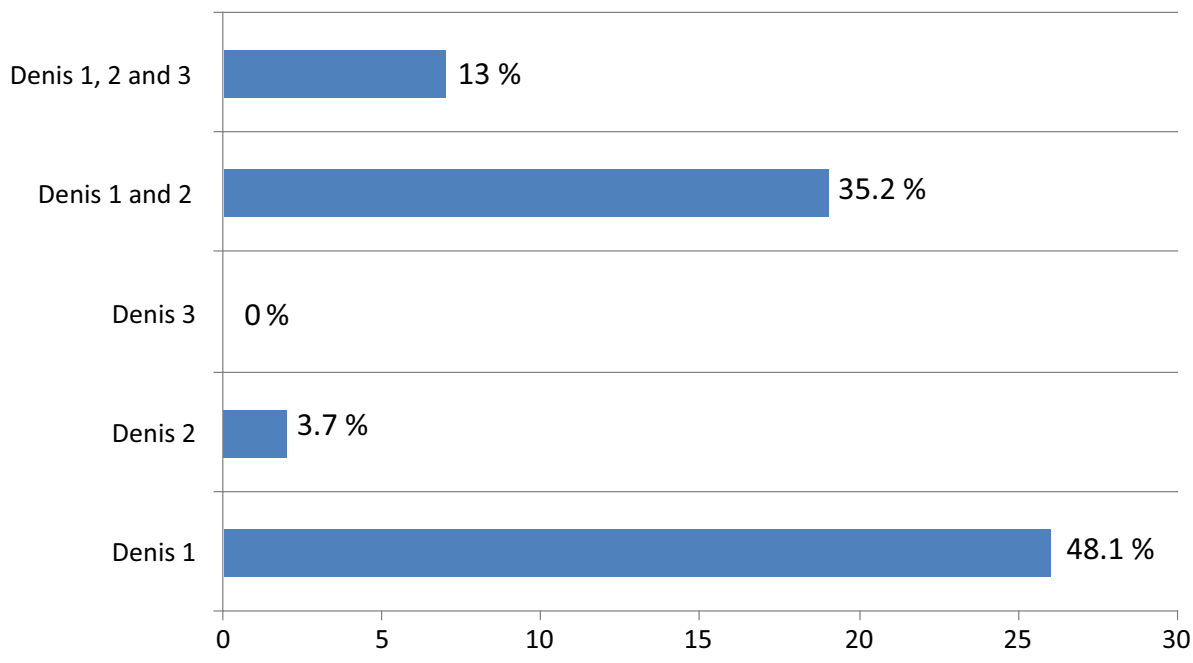

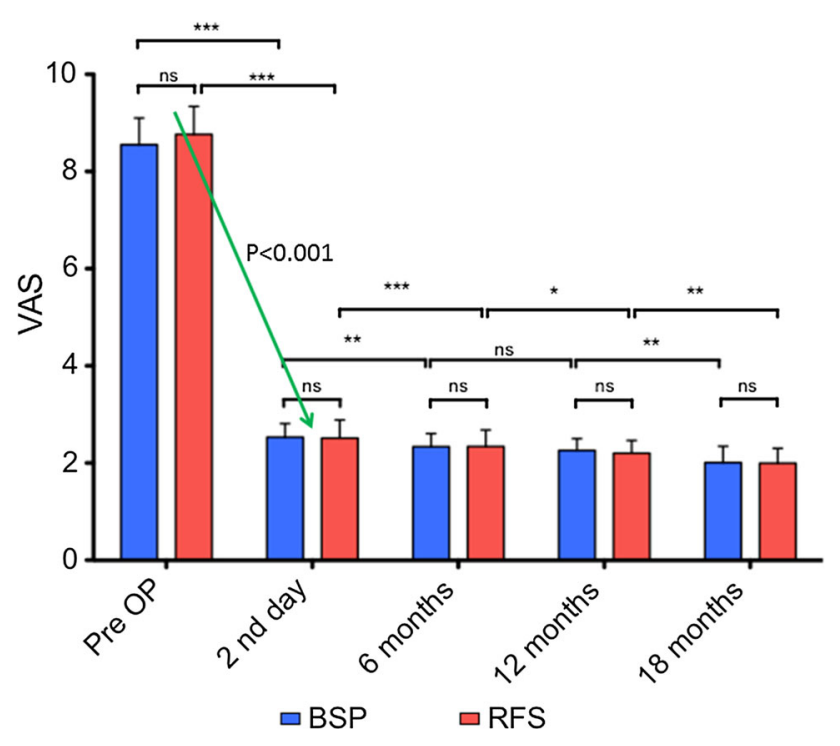

Fig. 5 Shows the means of pain intensity over time for the BSP group and RFS group as a bar chart, supplemented with the respective standard deviation as an indicator of error. The pain reduction on the 2 nd postoperative day is significant $(p<0.001)$ and is sustained over the course of 18 months, applying equally to both procedures. $* p<0.05, * * p<0.005$, and $* * * p<0.0005$

a marked reduction in pain has been demonstrated for all methods [6-10, 13, 14, 16, 20-23]. In the absence of the disabling pain, the patients can generally be remobilised at an early stage and can then start participating in everyday life again, which means a marked improvement in their quality of life [24, 25]. We found this in all of our patients over the course, regardless of the method chosen.

As an alternative, patients can be treated conservatively, which is up to now the standard therapy for sacral insufficiency fractures. This kind of treatment generally results in good functional outcomes [26]. The problematical aspect of this kind of treatment including bed rest, walking on crutches and adjuvant analgesic therapy in elderly patients is an increased risk of severe complications such as venous thromboembolism, pneumonia, decubitus ulcers and muscle and bone degeneration [26].

However, the positive effect of sacroplasty can be counteracted by complications, with not always asymptomatic cement leakages at the forefront [8, 12, 27, 28], although most do remain free of symptoms [22, 29]. Cement leakage can be further reduced in BSP by the use of a balloon catheter, with which a cavity is created in the fracture zone and potentially leaking fracture gaps are compressed $[13,16,21,25]$. In the case of RFS, the highly viscous cement provides protection against cement leakages [14, 22]. Of further importance are the surgical approaches, the dorsal approach via the so-called short axis or the transiliac approach being most suitable in our opinion, depending on the respective fracture localisation and fracture extent [16]. In all of our patients, the fractures could be accessed easily and unproblematically via the short or transiliac axis. For isolated Denis type 2 fracture zones, in our population 3 of 57 (approx. 5\%), the transiliac approach appears to be most practical. Approaches via the so-called long axis are far more complex from an anatomical point of view [13, 22, 29, 30, 31] and in our view are unnecessary [16, 28]. As a far advanced rarefaction of bone structure is generally found in all patients with an insufficiency fracture, CT-guided augmentation with its better visualisation is more precise and, thus, lower in complications such as cement extravasation than an intervention with a C-arm alone [28, 32].

With regard to pain reduction, the amount of cement required and the rate of cement leakages, the radiofrequency method would appear to be superior to balloon kyphoplasty in the treatment of vertebral body fractures [33]. For the treatment of insufficiency fractures of the sacrum, in our patients there is no significant difference in pain reduction, the amount of cement required or the rate of cement leakages, which was $0 \%$ for both BSP and RFS. 
As a result of the inserted cement filling, on average $6.3 \mathrm{ml}$ for the BSP group and $6.1 \mathrm{ml}$ for the RFS group, an interlocking of the fracture zone and thus a reduction of micro-movements is achieved [34], leading to a reduction in pain [8]. The optimum amount of cement to use has yet to be clarified. In a biomechanical investigation series on 25 cadaveric specimens, it was shown that stability could be significantly increased after cement augmentation, but that it made no difference whether $3 \mathrm{ml}$ or more were injected into the respective fracture zone [35]. Since $3 \mathrm{ml}$ of cement is already biomechanically effective for stabilisation [35], a possible reduction of the amounts of cement for BSP and RFS is conceivable and should be investigated in further studies to determine whether an equally good reduction of pain is achieved.

With regard to the complications and a mortality of $10 \%$ after 18 months of follow-up, there was no difference between the BSP group and the RFS group. Compared with a previous study in which there was a mortality of $23.5 \%$ after 12 months, the benefit of cement augmentation over conservative therapy in patients with a pain level $>5$ points on the VAS is marked [25].

BSP and RFS are minimally invasive procedures that enable reliable cement augmentation and achieve equally good, sustained pain reduction. The procedure should be used in which the surgeon has the most experience. After an unsuccessful attempt at conservative treatment, the option of cement augmentation should be considered in good time to improve quality of life.

\section{Compliance with ethical standards}

Conflict of interest None of the authors has any potential conflict of interest.

Open Access This article is distributed under the terms of the Creative Commons Attribution 4.0 International License (http://crea tivecommons.org/licenses/by/4.0/), which permits unrestricted use, distribution, and reproduction in any medium, provided you give appropriate credit to the original author(s) and the source, provide a link to the Creative Commons license, and indicate if changes were made.

\section{References}

1. Lourie H (1982) Spontaneous osteoporotic fracture of the sacrum. An unrecognised syndrome of the elderly. JAMA 248(6):715-717

2. Schindler OS, Watura R, Cobby M (2007) Sacral insufficiency fractures. J Orthopaedic Surg 15(3):339-346

3. Dasgupta B, Shah N, Brown H et al (1998) Sacral insufficiency fractures: an unsuspected cause of low back pain. Br J Rheumatol 37(7):789-793

4. Grasland A, Pouchot J, Mathieu A et al (1996) Sacral insufficiency fractures: an easily overlooked cause of back pain in elderly women. Arch Intern Med 156(6):668-674
5. Blake SP, Conners AM (2004) Sacral insufficiency fracture. Br J Radiol 77(922):891-896

6. Butler CL, Given CA 2nd, Michel SJ et al (2005) Percutaneous sacroplasty for the treatment of sacral insufficiency fractures. AJR Am J Roentgenol 184(6):1956-1959

7. Cho CH, Mathis JM, Ortiz O (2010) Sacral fractures and sacroplasty. Neuroimaging Clin N Am 20(2):179-186

8. Frey ME, DePalme MJ, Cifu DX et al (2008) Percutaneous sacroplasty for osteoporotic sacral insufficiency fractures: a prospective, multicenter, observational pilot study. Spine J 8(2):367-373

9. Pommersheim W, Huang-Hellinger F, Baker M et al (2003) Sacroplasty: a treatment for sacral insufficiency fractures. AJNR Am J Neuroradiol 24(5):1003-1007

10. Trouvin AP, Alcaix D, Somon T et al (2012) Analgesic effect of sacroplasty in osteoporotic sacral fractures: a study of six cases. Joint Bone Spine 79(5):500-503

11. Whitlow CT, Mussat-Whitlow BJ, Mattern CWT et al (2007) Sacroplasty versus vertebroplasty: comparable clinical outcomes for the treatment of fracture-related pain. AJNR Am J Neuroradiol 28(7):1266-1270

12. Bastian JD, Keel MJ, Heini PF et al (2012) Complications related to cement leakage in sacroplasty. Acta Orthop Belg 78(1):100-105

13. Andresen R, Radmer $S$, Kamusella $P$ et al (2012) Interventional pain relief using Balloon-Kyphoplasty in patients with osteoporotic-based fatigue fractures of the os sacrum. Fortschr Röntgenstr 184(1):32-36 (article in German)

14. Andresen R, Lüdtke CW, Radmer S et al (2015) Radiofrequency sacroplasty (RFS) for the treatment of osteoporotic insufficiency fractures. Eur Spine J 24(4):759-763

15. Denis F, Davis S, Comfort T (1988) Sacral fractures: an important problem. Retrospective analysis of 236 cases. Clin Orthop Relat Res 227:67-81

16. Andresen R, Radmer S, Kamusella P et al (2012) Treatment of Denis 1,2 and 3 insufficiency fracture zones of the os sacrum. Individual approaches adapted to the course of the fracture in CTassisted balloon sacroplasty. Osteol 21(3):168-173

17. Garant M (2002) Sacroplasty: a new treatment for sacral insufficiency fracture. J Vasc Interv Radiol 13(12):1265-1267

18. Deen HG, Nottmeier EW (2005) Balloon kyphoplasty for treatment of sacral insufficiency fractures. Report of three cases. Neurosurg Focus 18(3):1-5

19. Andresen R, Lüdtke CW, Kamusella P (2013) Radiofrequenzsakroplastie zur Versorgung einer einseitigen Denis 1 Insuffizienzfraktur. Osteoporose Rheuma aktuell 2:16-19 (article in German)

20. Kortman K, Ortiz O, Miller T et al (2013) Multicenter study to assess the efficacy and safety of sacroplasty in patients with osteoporotic sacral insufficiency fractures or pathologic sacral lesions. J Neurointerv Surg 5(5):461-466

21. Shah RV (2012) Sacral kyphoplasty for the treatment of painful sacral insufficiency fractures and metastases. Spine J 12(2):113-120

22. Eichler K, Zangos S, Mack MG et al (2014) Outcome of longaxis percutaneous sacroplasty for the treatment of sacral insufficiency fractures with a radiofrequency-induced, highviscosity bone cement. Skeletal Radiol 43(4):493-498

23. Bayley E, Srinivas S, Boszczyk BM (2009) Clinical outcomes of sacroplasty in sacral insufficiency fractures: a review of the literature. Eur Spine J 18(9):1266-1271

24. Babayev M, Lachmann E, Nagler W (2000) The controversy surrounding sacral insufficiency fractures: to ambulate or not to ambulate? Am J Phys Med Rehabil 79(4):404-409

25. Andresen R, Radmer S, Lüdtke CW et al (2015) Conservative therapie versus $\mathrm{CT}$ guided balloon sacroplasty in the treatment of 
insufficiency fractures of the sacrum. Osteol 24(2):92-98 (article in German)

26. Lin JT, Lane JM (2003) Sacral stress fractures. J Womens Health 12(9):879-888

27. Barber SM, Livingston AD, Cech DA (2013) Sacral radiculopathy due to cement leakage from percutaneous sacroplasty, successfully treated with surgical decompression. J Neurosurg Spine 18(5):524-528

28. Prokop A, Andresen R, Chmielnicki M (2016) Balloonsacroplasty: C-arm or CT controlled application?: Experience with 46 patients. Unfallchirurg 119(11):929-935 (article in German)

29. Klingler JH, Kluge P, Sicar R et al (2013) First experience using navigation-guided radiofrequency kyphoplasty for sacroplasty in sacral insufficiency fractures. Fortschr Röntgenstr 185(8):733-740

30. Binaghi S, Guntern D, Schnyder P et al (2006) A new, easy, fast, and safe method for CT-guided sacroplasty. Eur Radiol 16(12):2875-2878
31. Smith DK, Dix JE (2006) Percutaneous sacroplasty: long axis injection technique. AJR Am J Roentgenol 186(5):1252-1255

32. Grossterlinden L, Begemann PG, Lehmann W et al (2009) Sacroplasty in a cadaveric trial: comparison of CT and fluoroscopic guidance with and without balloon assistance. Eur Spine J 18(8): 1226-1233

33. Petersen A, Hartwig E, Koch EM, Wollny M (2016) Clinical comparison of postoperative results of balloon kyphoplasty (BKP) versus radiofrequency-targeted vertebral augmentation (RF-TVA): a prospective clinical study. Eur J Orthop Surg Traumatol 26(1):67-75

34. Whitlow CT, Yazdani SK, Reedy ML et al (2007) Investigating sacroplasty: technical considerations and finite element analysis of polymethylmethacralate infusion into cadaveric sacrum. AJNR Am J Neuroradiol 28(6):1036-1041

35. Richards AM, Mears SC, Knight TA et al (2009) Biomechanical analysis of sacroplasty: does volume or location of cement matter? AJNR Am J Neuroradiol 30(2):315-317 